\title{
Analysis of the prolonged infusion of DFP-10917, a deoxycytidine analog, as a therapeutic strategy for the treatment of human tumor xenografts in vivo
}

\author{
KENZO IIZUKA, CHUN ZHANG, KOKORO ESHIMA, CHENG JIN, \\ KIYOSHI ESHIMA and MASAKAZU FUKUSHIMA
}

Division of Oncology Research and Development, Delta-Fly Pharma Inc., Kawauchi-cho, Tokushima 771-0116, Japan

Received July 7, 2017; Accepted January 12, 2018

DOI: $10.3892 /$ ijo.2018.4246

\begin{abstract}
C-cyano-2'-deoxy-1- $\beta$-D-arabino-pentofranocylcytosine (DFP-10917, CNDAC) is a 2'-deoxycytidine analog with antitumor activity against various tumor cells. However, a clinically available therapeutic regimen for this compound needs to be established and its functional mechanisms in relation to the dosing schedule need to be clarified. In this study, we evaluated the antitumor activity and toxicity of DFP-10917 by varying the dose and administration schedule in human solid tumor and leukemia xenografts in vivo. Compared to a 1-day infusion with a high-dose of DFP-10917 (30 mg/kg/day), a prolonged 14-day infusion with a low-dose $(4.5 \mathrm{mg} / \mathrm{kg} /$ day $)$ exerted superior tumor growth inhibitory effects without decreasing the body weights of mice in our human tumor xenograft model. In addition, we found that a 14-day infusion of low-dose DFP-10917 markedly prolonged the lifespan of nude mice bearing both acute leukemia and ovarian cancer cellderived tumors. On the other hand, gemcitabine (GEM) and cytosine arabinoside (Ara-C), which are similar deoxycytidine analogs and are widely used clinically as standard regimens, exerted less potent antitumor effects than DFP-10917 on these tumors. To elucidate the possible functional mechanisms of the prolonged infusion of DFP-10197 compared with that of GEM or Ara-C, the rate of DNA damage in CCRF-CEM and HeLa cells treated with DFP-10917, Ara-C and GEM was detected using a comet assay. DFP-10917, at a range of 0.05 to $1 \mu \mathrm{M}$, induced a clear tailed-DNA pattern in both the CCRF-CEM and HeLa cells; Ara-C and GEM did not have any effect. It was thus suggested that a low concentration and long-term exposure to DFP-10917 aggressively introduced the fragmentation
\end{abstract}

Correspondence to: Dr Masakazu Fukushima, Division of Oncology Research and Development, Delta-Fly Pharma Inc., 37-5 Nishikino Miyajima, Kawauchi-cho, Tokushima 771-0116, Japan E-mail: fukushima1206@delta-flypharma.co.jp

Key words: DFP-10917, CNDAC, deoxycytidine analog, leukemia cell, continuous infusion, comet assay, DNA strand breaks, G2/M arrest of DNA molecules, namely the so-called double-strand breaks in tumor cells, leading to potent cytotoxicity. Moreover, treatment with DFP-10917 at a low-dose with a long-term exposure specifically increased the population of cells in the G2/M phase, while GEM reduced this cell population, suggesting a unique function (G2/M arrest) of DFP-10917. On the whole, our findings indicate that the prolonged infusion of low-dose DFP-10917 mainly displays a novel functional mechanism as a DNA-damaging drug and may thus prove to be useful in the treatment of cancer patients who are resistant to other cytosine nucleosides, or in patients in which these other nucleosides have been shown to be ineffective.

\section{Introduction}

Antitumor nucleosides, particularly the deoxycytidine analog, are key anticancer drugs which play an important role in the treatment of patients with solid tumors and leukemia. For instance, gemcitabine (GEM) and cytosine arabinoside (Ara-C) have been clinically used as a standard of care treatment in patients with pancreatic and non-small cell lung cancers (1-3), as well as in patients with and acute myeloid leukemia (AML) (4-8). A well-accepted cytotoxic mechanism of these drugs involves the inhibition of DNA biosynthesis through their incorporation into DNA molecules or the inhibition of DNA polymerases following the conversion to their tri-phosphate forms in cancer cells. However, these drugs are rapidly inactivated by the cytidine deaminase (CDA) in normal and tumor tissues (8). Accordingly, relatively high-doses of these drugs via bolus injection is common clinical practice in patients to avoid such an inactivation; $1,000-1,500 \mathrm{mg} / \mathrm{m}^{2}$ of GEM and $2-3 \mathrm{~g} / \mathrm{m}^{2}$ of Ara-C as induction therapy are frequently administered to patients with pancreatic cancer and AML, respectively.

2'-C-Cyano-2'-deoxy-1- $\beta$-D-arabino-pentofranocylcytosine (DFP-10917, CNDAC) was developed in the early 1990s as a deoxycytidine analog $(9,10)$, which has shown potent antitumor effects on various murine and human tumors in vitro and in vivo (11). Similar to other cytidine nucleosides, such as GEM and Ara-C,DFP-10917 has been demonstrated to be efficiently phosphorylated to its mono-, di- and tri-phosphate forms and is incorporated into the DNA of tumor cells in vitro (12). As 
regards the behavior of the triphosphate form of DFP-10917, following incorporation into DNA, Hayakawa et al speculated that it would chemically terminate an enzymatic DNA-chain elongation (13) and for this, there are some supporting data that DFP-10917 induces DNA double-strand breaks and G2 cell cycle arrest in tumor cells in vitro (14-17). On the other hand, a major functional mechanism of GEM and Ara-C has been estimated to be the direct inhibition of DNA polymerases, rather than their incorporation into DNA in tumor cells, affecting DNA synthesis (18-20).

However, such reports mentioned above, including those on GEM, Ara-C and DFP-10917, have focused on the clarification of their drug-induced functional mechanisms in tumor cells in vitro. However, the exact clinically available treatment regimen using these compounds which would prove to be most effective for cancer patients remains to be established. In addition, the functional mechanisms related to the drug schedule need to be elucidated.

Thus, the aim of this study was to investigate the optimal application dose and the treatment schedule for DFP-10917, which would be useful for the treatment of hospitalized patients with malignant tumors, including AML and advanced lung and pancreatic cancer. For this purpose, we developed human tumor xenograft models and aimed to confirm the association between the dose intensity with the dosing schedule, and elucidate the novel functional mechanisms of DFP-10917 compared to other deoxycytidine analogs.

\section{Materials and methods}

Chemicals. DFP-10917 (CNDAC) was manufactured by Delta-Fly Pharma Inc. (Tokushima, Japan). Ara-C and GEM were purchased from Sigma-Aldrich Inc. (St. Louis, MO, USA). Paclitaxel and cisplatin (CDDP) were purchased from Wako Pure Chemical Industries, Ltd. (Osaka, Japan). Decitabine, an inhibitor of DNA methyltransferase, was kindly provided by Otsuka Pharmaceutical Co. Ltd. (Tokyo, Japan). The comet assay $^{\mathrm{TM}}$ kit was obtained from Trevigen Inc. (Gaitherburg, MD, USA). All other chemical and biochemical materials were commercial products.

Tumor cells. The human MV-4-11 and CCRF-CEM leukemia cells, and the U937 lymphoma cells were purchased from Dai-Nippon Sumitomo Pharmaceutical Co. Ltd. (Osaka, Japan). The human colon cancer KM20C cells, lung cancer Lu-99 and Lu-61 cells were obtained from JCRB Cell Bank (National Institutes of Biomedical Innovation, Health and Nutrition, Japan). The human pancreatic cancer PAN-4 cells were obtained from the Central Institute for Experimental Animals (Kawasaki, Japan). Although the KM20C cells are considered to have been contaminated and are mixed rectosigmoid adenocarcinoma cells, and the data regarding the PAN-4 cells have not been disclosed, we decided to use these cells in our study, as it was considered that this contamination and these undisclosed data would have no influence on the comparative experiments. Human cervical cancer HeLa cells were obtained from ATCC (Global BioSource Center, Manassas, VA, USA). The SKOV-3 human ovarian cancer cells were kindly provided by Dr Mitsuaki Suzuki at Jichi-Medical University (Tochigi, Japan). These tumor cells were cultivated and maintained in RPMI-1640 medium containing $10 \%$ fetal bovine serum. Human solid tumor xenografts were prepared by the serial implantation of cells in vitro into the right axilla of nude mice at 3-week intervals until analysis.

Animals. A total of 135 male BALB/cA Jcl-nu mice and 190 male C.B-17/Icr-scid Jcl mice (5 weeks old, weighing 17.2-24.6 g), were purchased from KREA Japan, Inc. (Tokyo, Japan) and maintained on a commercial diet and autoclaved water, made available ad libitum. The care and treatment of the animals were in accordance with the guidelines issued by the Science and International Affairs Bureau of the Japanese Ministry of Education, Science, Culture and Sports. The experimental protocol was carried out following the approval of the Institutional Animal Ethics Committee at the research facility of Delta-Fly Pharma Inc.

Antitumor experiments. Groups of 6 or 7 nude mice were used. The KM20C, Lu-99, MV-4-11 and U937 tumor xenografts were prepared, respectively, by the subcutaneous implantation ( 2x2 mm fragments of tumor slices) into the right axilla of BALB/cA Jcl-nu mice. When the tumor volume reached $\sim 200 \mathrm{~mm}^{3}$, DFP-10917 (30, 8 or $4.5 \mathrm{mg} / \mathrm{kg} /$ day) was continuously infused by an Alzet osmotic pump for 24 consecutive hours on days 1 and 8 , for 3 consecutive days on days 1 and 15 , or for 14 consecutive days, or DFP-10917 (500 mg/kg/day) was administered via bolus injection on days 1 and 8 . Ara-C $(100 \mathrm{mg} / \mathrm{kg}$ ) was administered via intravenous (i.v.) injection on days $1-5$ and $8-12$, and GEM (300 mg/kg) was administered via i.v. injection on days 1 and 8 . Following drug treatment, the condition of the mice was monitored daily for 30 days. The longest tumor diameter formed by the KM20C cells was $18.51 \mathrm{~mm}$ and the maximum tumor volume was $2750.75 \mathrm{~mm}^{3}$. None of the mice developed multiple tumors. The tumor volume $\left[1 / 2 \mathrm{x}\right.$ (the major axis) $\mathrm{x}$ (the minor axis) $\left.{ }^{2}\right]$ was measured twice a week throughout the treatment period (14 days), and the relative tumor volume (RTV) was calculated as follows: RTV = (mean tumor volume during therapy) $/($ mean tumor volume at the start of therapy). The antitumor effects of DFP-10917, Ara-C and GEM were estimated by the following equation: Mean inhibition rate of tumor growth $(\mathrm{IR}, \%)=[1-($ mean RTV of drug-treated group/mean RTV of control group) $\mathrm{x} 100]$.

Survival experiments. For the U937 lymphoma cells, groups of 10 C.B-17/Icr-scid Jcl mice were used. Prior to tumor cell implantation, $0.2 \mathrm{ml}$ of anti-mouse Asialo GM1 antibody [antibody to natural killer (NK) cells] was injected intraperitoneally into all mice. The following day (day 1), the U937 lymphoma cells $\left(1 \times 10^{7}\right.$ cells $\left./ 0.5 \mathrm{ml} / \mathrm{mouse}\right)$ were implanted into the intraperitoneal cavity of the mice. From day 2, DFP-10917 ( $4.5 \mathrm{mg} / \mathrm{kg} / \mathrm{day}$ ) was continuously infused for 14 days, Ara-C (100 $\mathrm{mg} / \mathrm{kg} /$ day) was administered via i.v. injection on days 3-7 and days $10-14$, and decitabine (1.0 mg/kg/day) was administered via intraperitoneal (i.p.) injection on days 3-5 and days 10-12. Following drug treatments, the survival of the mice was monitored daily for 90 days. The antitumor activity of the drug was evaluated as the survival effect (ILS, \%) by the following equation: ILS $(\%)=$ [mean survival days in drugtreated group/mean survival days in control (no treatment) 
group - 1] x100. As one of the endpoints, the survival times with the respective agents were comparatively investigated.

For another tumor model using intraperitoneally disseminated ovarian cancer (SKOV-3) cells, the tumor cells ( $2 \times 10^{7}$ cells $\left./ 0.5 \mathrm{ml} / \mathrm{mouse}\right)$ were implanted, and after $24 \mathrm{~h}$ of implantation the mice (C.B-17/Icr-SCID Jcl) were treated with DFP-10917 (4.5 mg/kg/day, 14 days), GEM (300 mg/kg/day, days 1 and 8), CDDP (7 mg/kg/day, days 1 and 8$)$ and paclitaxel $(50 \mathrm{mg} / \mathrm{kg} /$ day, day 1$)$ as a positive control under the scheduled time periods.

Evaluation of drug-related toxicity. The body weights of the tumor-bearing mice were measured as an index of drug-induced toxicity, and the rate $(\%)$ of changes in body weight (BWC) was calculated by the following equation: BWC $(\%)=[($ body weight on day $n)-($ body weight on day 0$)] /($ body weight on day 0$) \times 100$. The maximum body weight of the mice with tumors derived from the Lu-99 cells was $25.0 \mathrm{~g}$ at the beginning of the experiment and $29.9 \mathrm{~g}$ upon sacrifice.

Comet assay. According to the manual provided with the Comet assay kit (21), the drug-treated cells were fixed on a glass slide, and treated with lysis solution for $>1 \mathrm{~h}$. The slide glass containing the drug-treated cells was then moved to an electrophoresis instrument and the cells were exposed to $33 \mathrm{~V}$ and $300 \mathrm{~mA}$ electrophoresis for $20 \mathrm{~min}$, and then soaked in $0.4 \mathrm{M}$ Tris- $\mathrm{HCl}$ buffer ( $\mathrm{pH} 7.5$ ) for $\sim 10 \mathrm{~min}$. This procedure was repeated once more. After soaking in $70 \%$ ethanol for $5 \mathrm{~min}$, the glass slide was dried to yield a thin-layer film. Finally, $50 \mu \mathrm{l}$ aliquots of ethidium bromide solution $(20 \mu \mathrm{g} / \mathrm{ml})$ were dropped onto the glass slide. After a coverglass was placed on the glass slide, the migration rate of the drug-treated cells (50 cells) was observed with an analysis apparatus for Comet assay.

Evaluation of DNA fragmentation. The drug-induced fragmentation of DNA in the CCRF-CEM cells was evaluated by the rate of electrophorated DNA (\% tail DNA) and olive tail moment calculated by the following equation: Olive tail moment $=($ tail.mean-head $\cdot$ mean $) \times \%$ tail DNA/100.

Cell cycle analysis. The HeLa cells $\left(1 \times 10^{6}\right)$ were inoculated into 6 -well plates and treated with either 1 to $30 \mu \mathrm{M}$ of DFP-10917 or 0.03 to $0.3 \mu \mathrm{M}$ of GEM. Untreated cells were used as the control group. Viable cells were counted 24, 48 and $72 \mathrm{~h}$ after the inoculation to analyze the effects of the drug on cell cycle progression using a commercially available cell-cycle analyzer, FACSCalibur flow cytometer (Becton-Dickinson, Franklin Lakes, NJ, USA).

Statistical analysis. The significance of differences between groups with or without drug treatment was assessed using the generalized Wilcoxon test. A value of $\mathrm{P}<0.05$ was considered to indicate a statistically significant difference.

\section{Results}

Effect of infusion time on the antitumor activity of DFP-10917 in vivo. It is well known that the dosing schedule of drugs influences their antitumor activity and has adverse events on cancer patients $(22,23)$. In a preliminary experiment using KM20C tumor-bearing mice to determine the maximum tolerance dose (MTD) of DFP-10917 at various doses and administration schedules without death and a $-20 \%$ change in body weight, we found that the MTD was thus determined to be $500 \mathrm{mg} / \mathrm{kg} /$ day for i.v. bolus injection on days 1 and 8 , $30 \mathrm{mg} / \mathrm{kg} /$ day for 1-day continuous infusions on days 1 and $8,8 \mathrm{mg} / \mathrm{kg} /$ day for 3 -day continuous infusions on days 1 and 15 , and $4.5 \mathrm{mg} / \mathrm{kg} /$ day for 14-day continuous infusion (data not shown). Based on the results, we evaluated the antitumor activity and toxicity of the infusion time of DFP-10917 on the same KM20C human cancer xenografts in nude mice. As shown in Fig. 1A, no re-growth of tumors or body weight loss were observed during days 15-29 following the initiation of treatment with DFP-10917 for the 14-day continuous infusion schedule $(4.5 \mathrm{mg} / \mathrm{kg})$ compared to the other schedules [i.v. bolus injection $(500 \mathrm{mg} / \mathrm{kg}$, days 1 and 8$)$, 1-day continuous infusion (30 mg/kg, days 1 and 8 ), and 3-day continuous infusion $(8 \mathrm{mg} / \mathrm{kg}$, days 1 and 15)]; the prolonged (at least over 7 days) administration of DFP-10917 at a low-dose of $4.5 \mathrm{mg} / \mathrm{kg} /$ day resulted in the most potent antitumor activity with an $>70 \%$ inhibition of tumor growth (IR) compared to its shorter ( 1 to 3 days) administrations. These results thus suggest that in oder to achieve the maximal response against human cancers, DFP-10917 should be administered by longterm infusion (14 days) at a lower dose $(4.5 \mathrm{mg} / \mathrm{kg})$.

Re-growth rates of colon tumors following treatment with DFP-10917 in various dosing schedules. In the same antitumor experiment, we observed the re-growth rates of KM20C tumors on days 15, 22 and 29 after the infusion of DFP-10917 with the 1- to 14-day schedules. As shown in Fig. 1B, the IR of tumor growth after a 1-day infusion with high-dose (30 mg/kg/day) DFP-10917 significantly decreased from $70.1 \%$ (on day 15) to $45.7 \%$ on day 29 . By contrast, the 14-day infusion of $4.5 \mathrm{mg} / \mathrm{kg} /$ day DFP-10917 resulted in an increased IR from $79.6 \%$ (on day 15 ) to $98.6 \%$ (on day 29), suggesting that the prolonged infusion with low-dose DFP-10917 prevented tumor re-growth after the terminated administration.

Effect of the prolonged infusion of DFP-10917 on human lung cancer xenografts. GEM is mainly used to treat patients with advanced pancreatic and lung cancer as one of the firstline treatment regimens $(24,25)$. However, such a treatment is generally ineffective and patients become resistant to this drug $(26,27)$. Therefore, there is an urgent need for the development of a novel treatment regimen with which to control the progression of pancreatic and lung cancer. In this study, we examined the efficacy of DFP-10917 in comparison to GEM of one of the deoxycytidine analogs by using Lu-99 human lung cancer xenografts. DFP-10917 was found to control and/or suppress the growth of Lu-99 tumor throughout the therapeutic periods up to 29 days, while GEM exhibited limited efficacy on this tumor, as was expected (Fig. 2). In separate experiments for comparing DFP-10917 and GEM by using PAN-4 pancreatic and Lu-61 lung cancer xenografts, the same dose rates and treatment schedules for DFP-10917 and GEM resulted in an 84 and 59\% IR, respectively in PAN-4-derived tumors, and in 91 and $17 \%$ IR, respectively, in Lu-61-derived tumors (data not shown). Throughout these experiments, the prolonged 14-day 


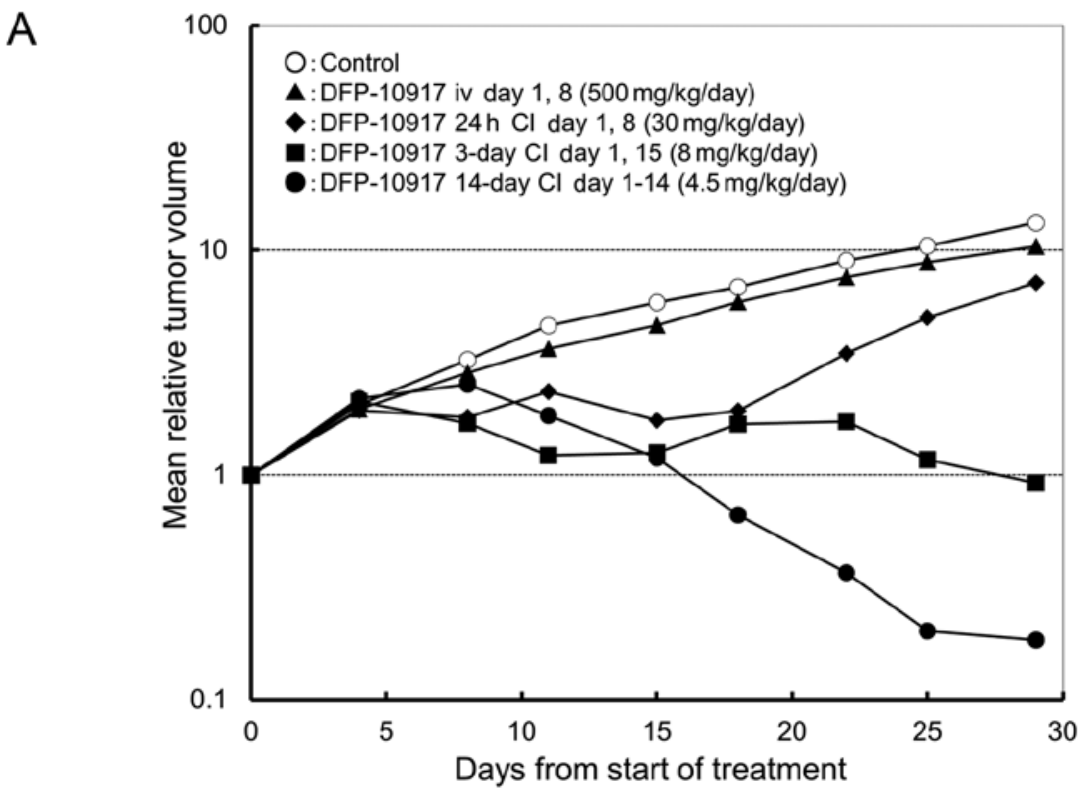

B

Day 15

Day 22

Day 29

RTV

RTV

RTV

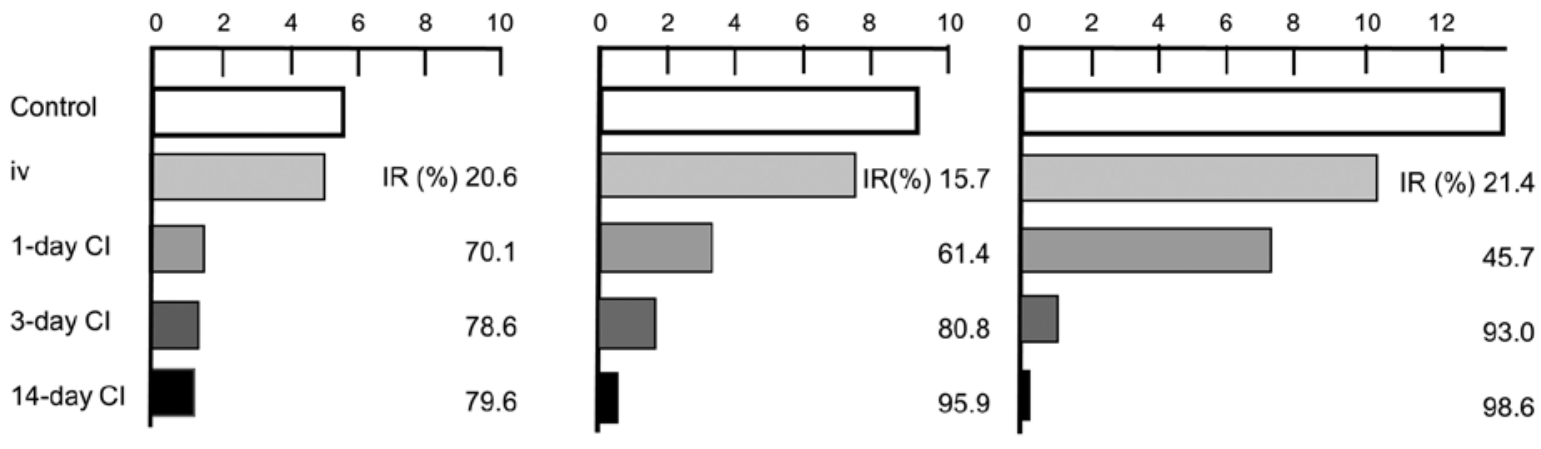

Schedule of drug-treatment and observation

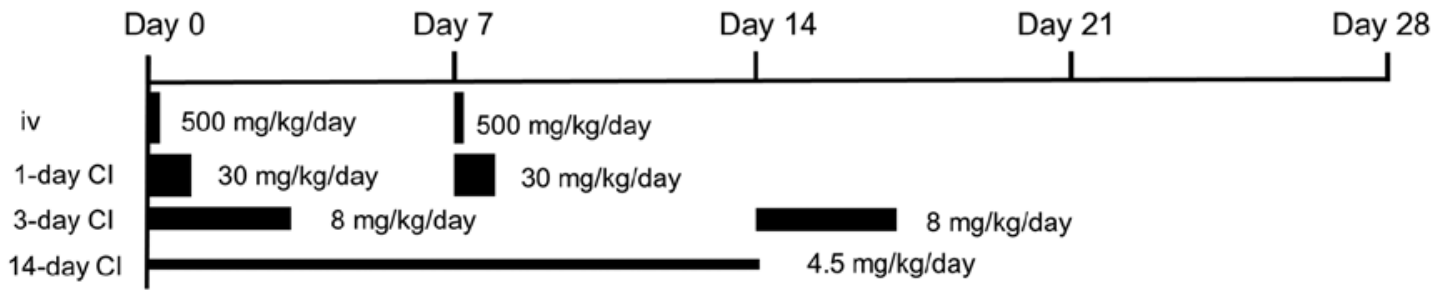

Figure 1. Effect of infusion time on the antitumor activity of DFP-10917 in KM20C human tumor xenografts in nude mice. The maximum tolerance dose (MTD) dose of DFP-10917 was infused for 1 day (30 mg/kg/day) x2, 3 days $(8 \mathrm{mg} / \mathrm{kg} /$ day) x2, and 14 days $(4.5 \mathrm{mg} / \mathrm{kg} /$ day), respectively, to KM20C tumor-bearing mice from 7 days after implantation. Relative tumor volume (RTV) was calculated as follows: $\mathrm{RTVn}=(\mathrm{TV}$ on day $\mathrm{n}) /(\mathrm{TV}$ on day 0$), \mathrm{n}=4,8,11,15,18,22,25$ and 29. (A) On day 15, the tumor growth inhibitory effects of DFP-10917 were evaluated for each treatment group, and thereafter, (B) the regrowth rate of the tumors was measured on days 15, 22 and 29, respectively. Data represent mean values of relative tumor volume for 7 mice.

infusion of DFP-10917 was suggested to have an antitumor activity comparative to that of GEM.

Effect of the long-term infusion DFP-10917 on hematological tumor cells in mice. Ara-C has been a standard of care for the treatment of patients with AML. A bolus injection of highdoses of Ara-C has been applied due to the rapid inactivation by cytidine deaminase. We thus comparatively evaluated the anticancer activity of DFP-10917 and Ara-C in the U937 and MV-4-11 cells tumors (solid forms in both cases). As shown in Fig. 3, the prolonged infusion of DFP-10917 markedly affected both U937 and MV-4-11 tumor xenografts with a 98.8 and 98.7\% IR, respectively, compared to treatment with Ara-C which yieled an 83 and $43.6 \%$ IR, respectively. It is worth mentioning that DFP-10917 markedly abolished tumor growth over the 14-day therapeutic period.

Comparative survival effect of DFP-10917 on ascitic U937 and SKOV-3 tumor xenografts in mice. As the ultimate objective of drug treatment in advanced cancers is the achievement of prolonged survival with a good quality of life (QOL), the effects of DFP-10917 by 14-day infusion on survival were 


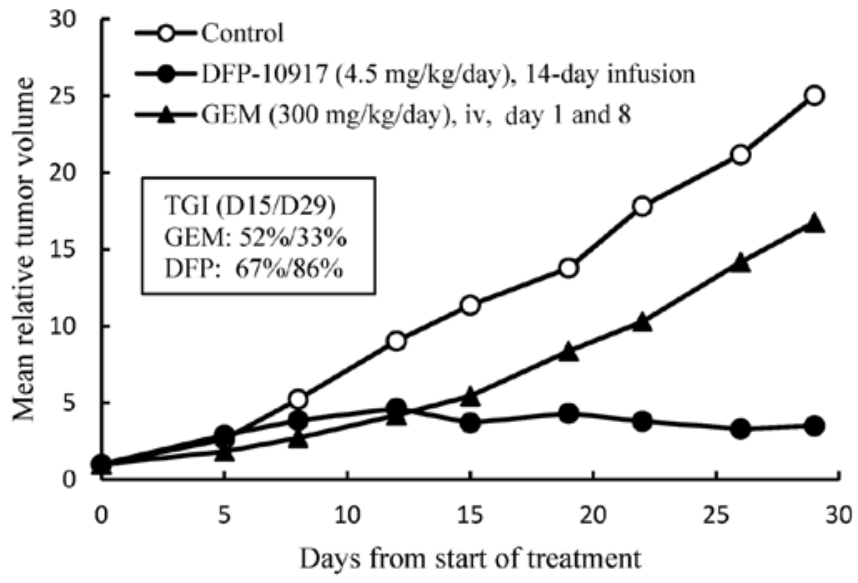

Figure 2. Antitumor effect of DFP-10917 and gemcitabine on Lu-99 human lung cancer xenografts resistant to gemcitabine. In this therapeutic experiment, a low-dose ( $4.5 \mathrm{mg} / \mathrm{kg} / \mathrm{day})$ of DFP-10917 was continuously infused for 14 days, and a high-dose ( $300 \mathrm{mg} / \mathrm{kg} / \mathrm{day})$ of gemcitabine was administered intravenously (i.v.) weekly for 2 times. Values are the means \pm SD for 6 mice. Relative tumor volume (RTV) was calculated as follows: RTVn $=(\mathrm{TV}$ on day $n) /($ TV on day 0$), n=5,8,12,15,19,22,26$ and 29.

examined on ascitic U937 leukemia cells. As shown in Table I, DFP-10917, Ara-C and decitabine led to a 165, 127 and 33\% increase in lifespan (ILS), respectively; this suggests a favorable pro-survival effect of DFP-10917 compared with Ara-C and decitabine. We further evaluated the effects of DFP-10917, GEM, CDDP and paclitaxel as standards of care for ovarian cancer, in a disseminated ascitic form of SKOV-3 ovarian cancer cells in mice (Table I). The prolonged infusion of DFP-10917 was also demonstrated to significantly increase the long-term survival by $234 \%$ compared to GEM (12\%), CDDP (39\%) and paclitaxel (47\%). Throughout two therapeutic experiments, the prolonged infusion of DFP-10917 at a lowdose clearly prolonged the survival time in both leukemia cells and intraperitoneally disseminated solid tumors, suggesting its potential clinical benefit for patients with cancer.

DNA double-strand breaks in human cancer cells following treatment with DFP-10917. To investigate the cytotoxic mechanisms of the prolonged infusion of DFP-10917 compared to other deoxycytidine analogs, such as Ara-C and GEM, DNA strand-breakage following the continuous exposure to DFP-10917 and Ara-C or GEM was investigated by comet assay (20) in human leukemia CCRF-CEM cells and solid cervical cancer HeLa cells. In the CCRF-CEM cells, $1 \mu \mathrm{M}$ DFP-10917 ( $\mathrm{IC}_{50}$ value) induced marked DNA fragmentation with $26.88 \pm 12.84$ of $\%$ tail, while 1 to $10 \mu \mathrm{M}\left(\mathrm{IC}_{50}\right.$ and IC70 values) Ara-C induced limited DNA fragmentation with $\sim 6.95 \pm 6.65$ of \% tail DNA (Fig. 4). Similarly, DNA damage as an indicator of DNA strand breaks by $0.05 \mu \mathrm{M}$ DFP-10917 and $0.03 \mu \mathrm{M}$ GEM (both $\mathrm{IC}_{50}$ values) was evaluated and calculated as \% tail DNA using HeLa cells. The rate of DNA fragmentation (\% tail DNA) for 72-h incubation was 7.16 \pm 6.86 for the control group, $21.69 \pm 12.67$ for the DFP-10917 group and $8.37 \pm 6.45$ for the GEM group (Fig. 5). These result suggest that DFP-10917 induces potent DNA damage as evaluated by DNA fragmentation (comet assay) compared to Ara-C and GEM.
Effect of DFP-10917 and GEM on cell-cycle of human tumor cells. To investigate whether DSFP-10917 and GEM, similar cytidine analogs, have similar functions in tumor cells, HeLa cells was exposed for various amounts of time to various concentrations of both drugs, and the numbers of treated cells in the G0/G1, S and G2M of the cell cycle were respectively determined by a cell cycle analyzer. As shown in Fig. 6, long-term exposure (72 h) to $1 \mu \mathrm{M}$ DFP-10917 significantly increased the numbers of cells in the $\mathrm{G} 2 / \mathrm{M}$ phase of the cell cycle (G2/M arrest), whereas a high-dose $(30 \mu \mathrm{M})$ and a shorter incubation time $(24 \mathrm{~h})$ with this drug resulted in a decrease in the numbers of cells in the $\mathrm{S}$ phase, suggesting the inhibition of DNA synthesis under such conditions. By striking contrast, GEM caused only a decrease in the numbers of cells in the $\mathrm{S}$ phase when used for $24 \mathrm{~h}$ at high $(0.3 \mu \mathrm{M})$ concentrations. GEM also did not increase the cell number in the $\mathrm{G} 2 / \mathrm{M}$ phase of the cell cycle. These results suggest that the functional mechanism of the prolonged exposure to low-dose DFP-10917 clearly differs from that of exposure to GEM or other deoxycytidine analogs.

\section{Discussion}

Of the anti-metabolites widely used in the treatment of cancers, antitumor nucleosides, such as Ara-C, GEM and decitabine have been recognized to play a vital role in the treatment of hematological and solid cancers as single agent and/or combined therapeutic regimens. The major mechanisms for the antitumor activity of these cytosine nucleosides is the inhibition of DNA replication or repair, which is much higher in tumor cells than in normal cells via the inhibition of key enzymes, such as DNA polymerases and ribonucleotide reductase or direct incorporation into DNA. However, due to the unfavorable intracellular metabolism (particularly catabolism) of these nucleosides, it would be important to establish suitable exposure conditions, such as dosage and the administration time, in order to reach a desirable antitumor activity with limited toxicity which leads to the objective exhibition of their DNA regulation mentioned above.

DFP-10917 (also kown as CNDAC) is a unique synthesized promising deoxycytidine analog which has been shown to exert potent anticancer activity against various murine and human tumors in vitro and in vivo $(9,11)$. Different from GEM and Ara-C, the cytotoxic mechanism of DFP-10917 has been speculated to be the induction of DNA strand breakage following its incorporation into DNA and the arrest in the G2/M phase of the cell cycle in treated tumor cells $(14,15)$. However, the association between the cumulative dosage and treatment schedule of DFP-10917 in order to exert a maximal antitumor activity has not been yet defined in vivo human tumor models. In this study, we thus evaluated the effects of cumulative dose and infusion schedule on the antitumor efficacy of DFP-10917 using KM20C human tumor xenografts in mice. As shown in Fig. 1, when a total of $63 \mathrm{mg} / \mathrm{kg}$ of DFP-10917 was administered over a 14-day therapeutic period, the prolonged continuous infusion (14 days) with the lowest dose $(4.5 \mathrm{mg} / \mathrm{kg} /$ day) resulted in the maximal tumor growth inhibition (tumor regression) with no drug-related toxicity in compared to 1-day infusion with the high-doses $(30 \mathrm{mg} / \mathrm{kg} /$ day, total of $60 \mathrm{mg} / \mathrm{kg}$ ) or 3-day infusion with the intermediate doses $(8 \mathrm{mg} / \mathrm{kg} / \mathrm{day}$, total of $48 \mathrm{mg} / \mathrm{kg})$. 


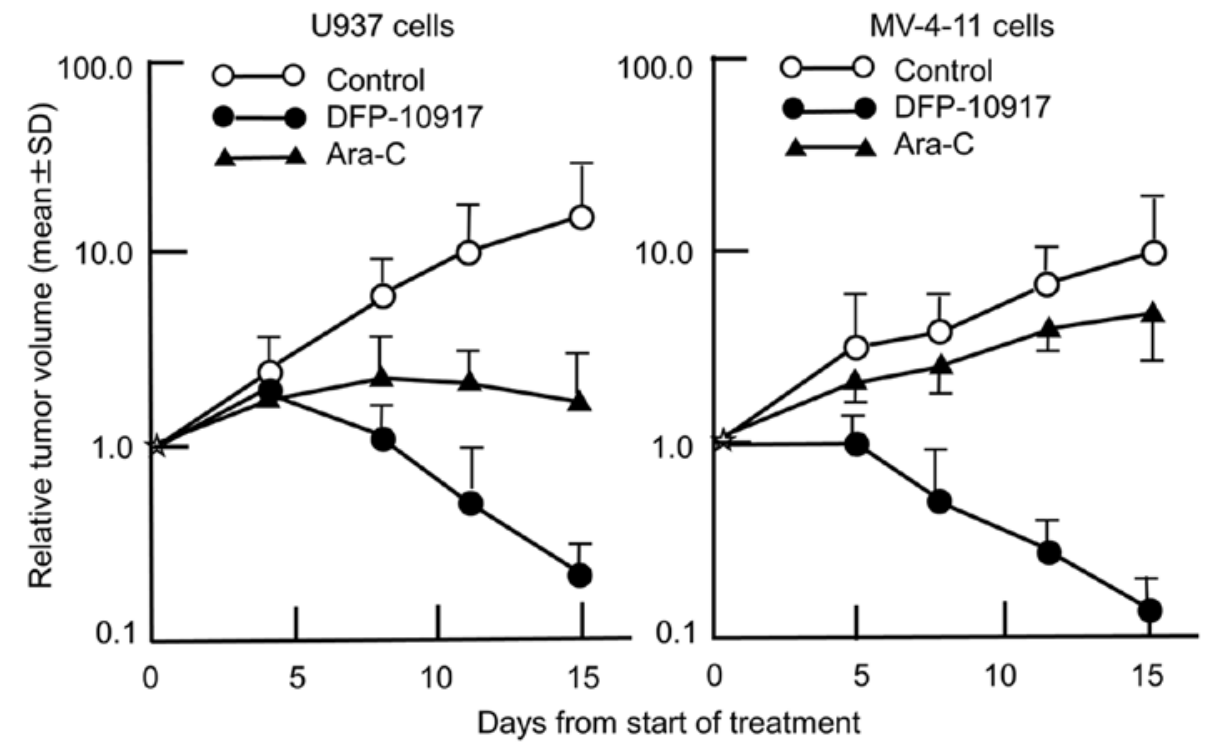

Figure 3. Anti-leukemic effect of DFP-10917 and cytosine arabinoside (Ara-C) on (A) U937 and (B) MV-4-11 human lymphoma xenografts. U937 and MV-4-11 cells were inoculated into mice as solid forms for 7 mice, respectively, and 7 days after implantation. DFP-10917 (4.5 mg/kg/day) was infused for 14 days, and Ara-C (100 mg/kg/day) was injected intravenously (i.v.) on days 1-5 and days 8-12. Relative tumor volume (RTV) was calculated as follows: $\mathrm{RTVn}=(\mathrm{TV}$ on day $\mathrm{n}) /(\mathrm{TV}$ on day 0$), \mathrm{n}=5,8,12$ and 15.
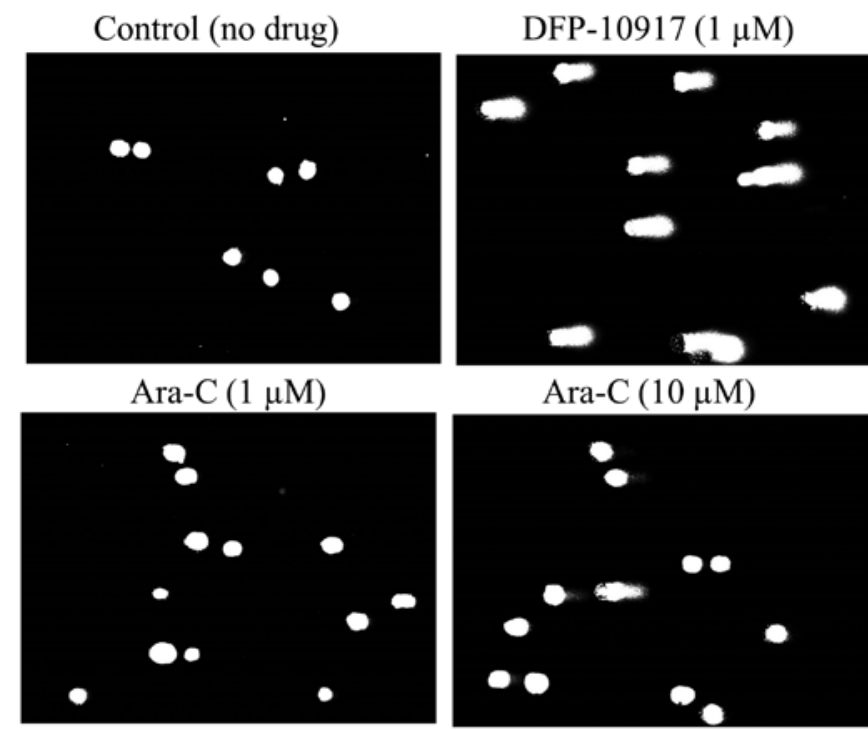

Ara-C $(10 \mu \mathrm{M})$
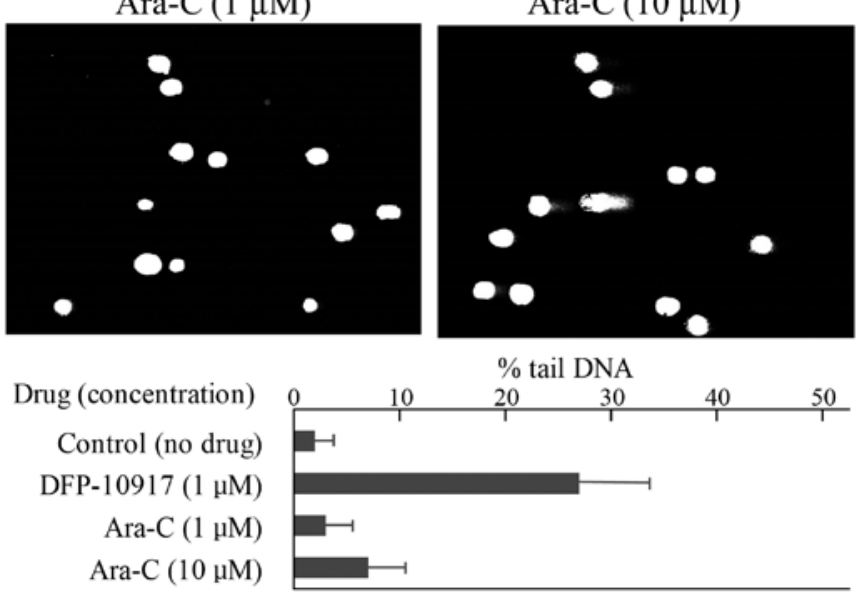

Figure 4. DNA fragmentation in CCRF-CEM cells treated with DFP-10917 and cytosine arabinoside (Ara-C) for $24 \mathrm{~h}$. CCRF-CEM cells $\left(2 \times 10^{5}\right)$ were inoculated into $20 \mathrm{ml}$ of culture flask and $24 \mathrm{~h}$ later, $1 \mu \mathrm{M}$ DFP-10917 and 1 to $10 \mu \mathrm{M}$ Ara-C $\left(\mathrm{IC}_{50-70}\right)$ were added to the flask, followed by further incubation for $24 \mathrm{~h}$. The cells were then collected and drug-induced DNA fragmentation in the cells was evaluated by the rate of electrophorated DNA (\% tail DNA).

Furthermore, the prolonged (14-day) infusion of DFP-10917 was comparatively evaluated in human lung cancer Lu-99 xenografts in which GEM showed limited antitumor activity. As shown in Fig. 2, the 14-day infusion of low-dose
(4.5 mg/kg/day) DFP-10917 reduced tumor volume, while the weekly intravenous injection of high-dose GEM $(300 \mathrm{mg} / \mathrm{kg})$ resulted in only a 33\% decrease on day 14 and $14 \%$ of tumor growth inhibition (TGI) on day 29 in the same therapeutic periods.

We were interested in investigating whether the prolonged continuous infusion of DFP-10197 at a lower dose also plays the same role in human leukemia cells in vivo compared to Ara- $\mathrm{C}$ which is a standard therapeutic drug used in the treatment of patients with AML, and comparatively evaluated the growth inhibitory effect of the 14-day infusion of low-dose DFP-10917 (4.5 mg/kg/day) and consecutive i.v. injection (days 1-5 and 8-12) of high-dose Ara-C (100 mg/kg/day) on U937 and MV-4-11 human leukemia tumor xenografts in nude mice, respectively. The prolonged infusion of low-dose DFP-10917 markedly suppressed tumor volume in both leukemia xenografts, and compared to DFP-10917, the repeated 5-day consecutive administration of Ara-C was less effective on these tumors (Fig. 3), suggesting that DFP-10917 may be useful for the treatment of leukemia.

In terms of finding the optimal dose of GEM in preclinical and clinical reports, there are various reports over the past 2-3 decades. Veerman et al (28) suggested that the prolonged infusion of GEM led to a better antitumor activity than bolus injections in vivo and that it showed promise of being active in clinical trials. On the other hand, Kirstein et al (29) showed that long-term survival was significantly diminished following continuous infusion compared with the short-term infusion of GEM, although treatment induced apoptosis following both short-term and continuous infusions in non-small cell lung cancer cells in vitro. In clinical trials, Rajdev et al (30) performed a phase I trial of GEM administered as a 96-h continuous intravenous infusion in patients with advanced carcinoma and lymphoma and concluded that the administration of GEM as a 96-h infusion resulted in a markedly different toxicity profile than when administered by a conventional 
Table I. Effects of DFP-10917 on the survival of mice with U937 or SKOV-3 human tumor xenografts.

\begin{tabular}{|c|c|c|c|c|c|c|}
\hline Cell line & Drug & $\begin{array}{c}\text { Dose } \\
(\mathrm{mg} / \mathrm{kg} / \text { day })\end{array}$ & Treatment & $\begin{array}{l}\text { No. of } \\
\text { mice }\end{array}$ & $\begin{array}{c}\text { Survival time } \\
\text { (days, mean } \pm \text { SD) }\end{array}$ & $\begin{array}{l}\mathrm{ILS}^{\mathrm{a}} \\
(\%)\end{array}$ \\
\hline \multirow{4}{*}{$\begin{array}{l}\text { U937 } \\
\text { (lymphoma) }\end{array}$} & Control & - & - & 10 & $32.9 \pm 30.5$ & - \\
\hline & DFP-10917 & 4.5 & s.c., days 3-17 & 10 & $87.2 \pm 6.1^{\mathrm{b}, \mathrm{c}, \mathrm{d}}$ & 165.0 \\
\hline & Ara-C & 100 & i.v., days 3-7, 10-14 & 9 & $74.4 \pm 15.5^{\mathrm{b}}$ & 127.0 \\
\hline & Decitabine & 1.0 & i.p., days $3-5,10-12$ (bid) & 10 & $43.8 \pm 24.7$ & 33.1 \\
\hline \multirow{5}{*}{$\begin{array}{l}\text { SKOV-3 } \\
\text { (ovarian carcinoma) }\end{array}$} & Control & - & - & 10 & $22.0 \pm 2.2$ & - \\
\hline & DFP-10917 & 4.5 & s.c., days $1-14$ & 10 & $73.5 \pm 4.6^{\mathrm{e}, \mathrm{f}, \mathrm{g}, \mathrm{h}}$ & 234.1 \\
\hline & Paclitaxel & 50 & i.v., day 1 & 10 & $32.3 \pm 7.9^{\mathrm{e}}$ & 46.8 \\
\hline & CDDP & 7 & i.v., days 1,8 & 10 & $30.6 \pm 4.7^{\mathrm{e}}$ & 39.1 \\
\hline & Gemcitabine & 300 & i.v., days 1,8 & 10 & $24.7 \pm 1.3^{\mathrm{e}}$ & 12.3 \\
\hline
\end{tabular}

U937 cells $\left(1 \times 10^{7}\right.$ cells $\left./ 0.5 \mathrm{ml} / \mathrm{mouse}\right)$ were implanted into intraperitoneal cavity of C.B-17/Icr-scid Jcl mice. After 2 days, the mice were treated with the drugs and the survival time of each mouse was then observed for 90 days. SKOV-3 cells $\left(2 \times 10^{7}\right.$ cells $\left./ 0.5 \mathrm{ml} / \mathrm{mouse}\right)$ were implanted into the intraperitoneal cavity of C.B-17/Icr-scid Jcl mice. After $24 \mathrm{~h}$, the mice were treated with the drugs and the survival time of each mouse was observed for at least 90 days. ${ }^{a}$ ILS indicates the increase in lifespan. ILS $(\%)=($ mean survival time of treatment group/mean survival time of control group - 1) x100. Significant differences were observed by the generalized Wilcoxon test as follows: ${ }^{\mathrm{b} C o n t r o l ~ v s . ~ D F P-10917 ~}$ $(\mathrm{P}<0.005)$; ${ }^{\mathrm{b}}$ control vs. Ara-C $(\mathrm{P}<0.05)$; ${ }^{\mathrm{c} A r a-C}$ vs. DFP-10917 $(\mathrm{P}<0.05)$; and ${ }^{\mathrm{d} d e c i t a b i n e ~ v s . ~ D F P-10917 ~}(\mathrm{P}<0.005)$. In addition, significant differences were observed by the generalized Wilcoxon test as follows: ${ }^{\circ}$ Control vs. DFP-10917 $(\mathrm{P}<0.0001)$; ${ }^{\mathrm{e}}$ control vs. paclitaxel $(\mathrm{P}<0.0005)$; ${ }^{\mathrm{e}}$ control vs. CDDP $(\mathrm{P}<0.0001)$; ${ }^{\mathrm{e}}$ control vs. gemcitabine $(\mathrm{P}<0.01)$; f $^{\mathrm{f}}$ aclitaxel vs. DFP-10917 ( $\left.<<0.0001\right)$; ${ }^{\mathrm{g}} \mathrm{CDDP}$ vs. DFP-10917 (P<0.0001) and ${ }^{\mathrm{h}}$ gemcitabine vs. DFP-10917 $(\mathrm{P}<0.0001)$.

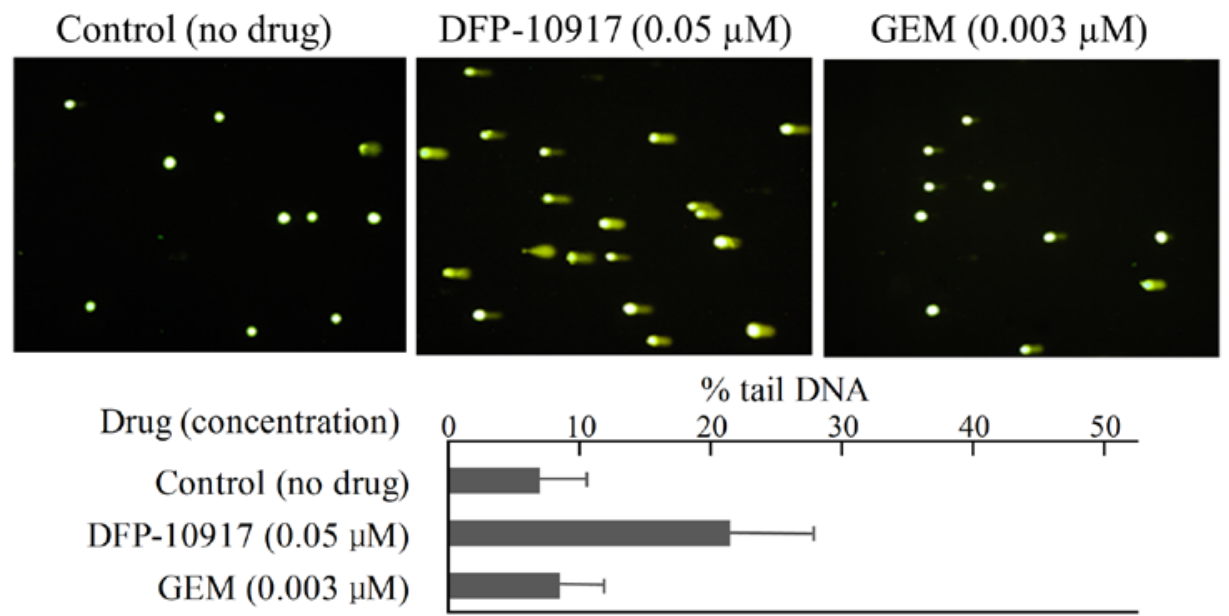

Figure 5. DNA damage in HeLa cells treated with $0.03 \mu \mathrm{M}$ DFP-10917 and $0.003 \mu \mathrm{M}$ gemcitabine (GEM) (both IC 50 values) for 24 h. HeLa cells $\left(1 \times 10^{6}\right)$ were inoculated into $20 \mathrm{ml}$ of culture flask and followed by further incubation for $72 \mathrm{~h}$. Thereafter, the drug-treated cells were collected and DNA fragmentation induced by the drug was analyzed by comet assay.

30-min infusion. In addition, a number of clinical studies have supported a short-time (30-min) infusion rather than a long-term (over $2.5 \mathrm{~h}$ ) infusion of GEM from the viewpoint of the survival and GEM-induced toxicity profiles in cancer patients $(31,32)$.

Ara- $\mathrm{C}$, the other deoxycytidine analog, is the standard of care for the treatment of patients with AML. Although there are few reports of the optimization of the dosing schedule of Ara-C in preclinical studies using leukemia cells, various clinical trials have been carried out to determine a suitable or optimal dosing schedules of Ara-C for patients with AML (33-44). Currently, for the treatment of patients with AML, the 7-day infusion of standard-dose Ara-C (100-200 $\left.\mathrm{mg} / \mathrm{m}^{2}\right)$ or the 6-day infusion of the 12-h high-dose Ara-C $\left(2,000 \mathrm{mg} / \mathrm{m}^{2}\right)$ in combination with anthracycline (idarubicin or daunorubicin) are conducted as induction therapy, and/or 3-h infusion of high-dose Ara-C (HiDAC, 3,000 mg/m²) every $12 \mathrm{~h} /$ day for 3 to 4 cycles is the consolidation therapy. Accordingly, the dose and schedule of GEM and Ara-C used in this in vivo study would reflect the clinical treatment regimen and the prolonged continuous infusion of low-dose DFP-10917 and may contribute to the treatment of patients with solid tumors or leukemia cells resistant or insensitive to standard of deoxycytidine analogs in future clinical studies.

As regards the molecular and pharmacological mechanisms of DFP-10917 (also known as CNDAC), although Azuma et al (14) and Liu et al (15) reported that DFP-10917 caused the DNA strand breaks and subsequent G2/M phase 


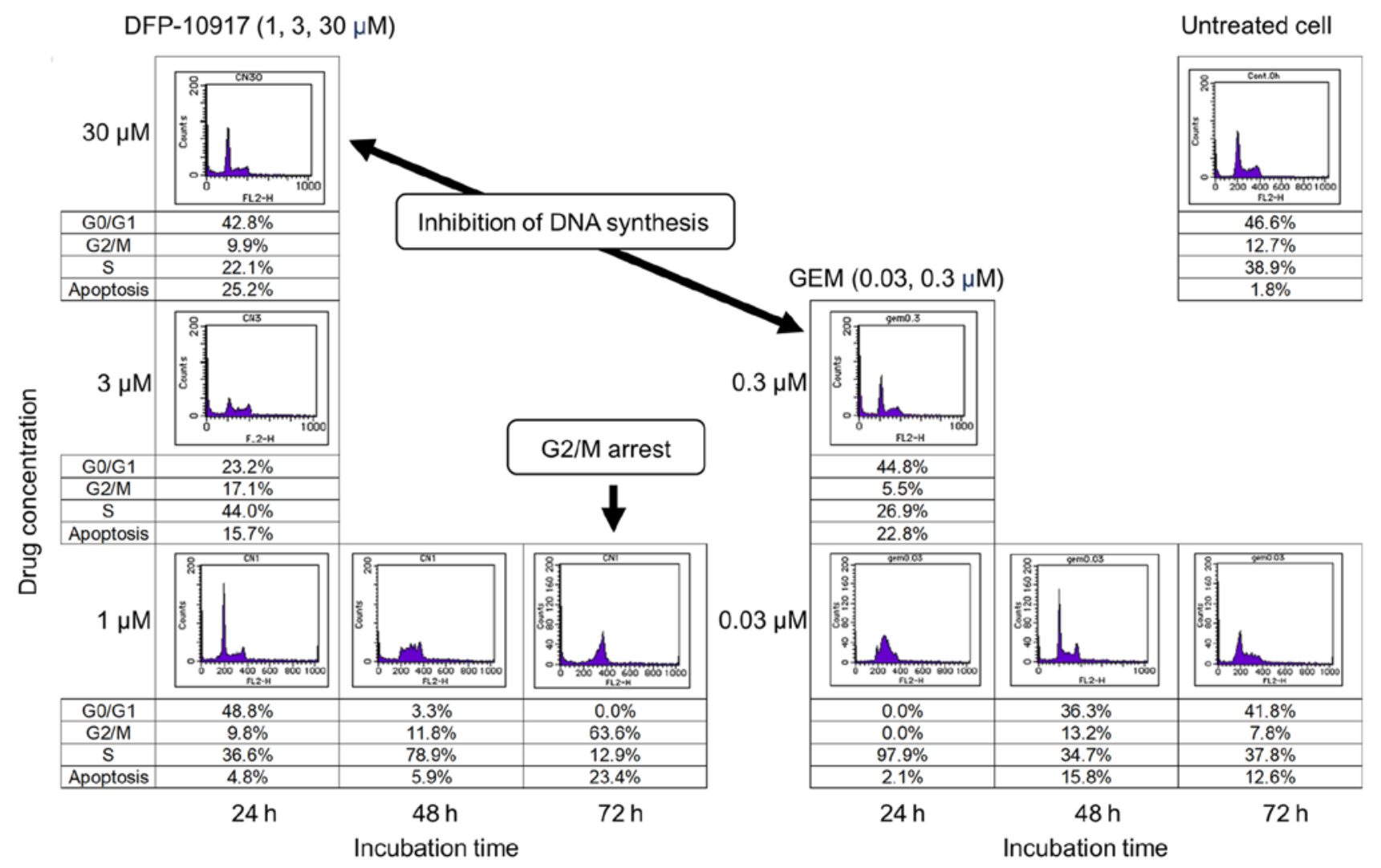

Figure 6. Effects of treatment with DFP-10917 and gemcitabine (GEM) on the cell cycle of HeLa cells. HeLa cells (1x10 $)$ were treated with 1 to $30 \mu \mathrm{M}$ DFP-10917 and 0.03 to $0.3 \mu \mathrm{M}$ GEM for 24, 48 and $72 \mathrm{~h}$, and the treated cells were then immediately collected and the distribution rate (\%) of cell number in G0/G1, S and G2/M fraction of drug-treated cells was measured using a cell cycle analyzer.

arrest of the cell cycle in DFP-10917-treated tumor cells, we evaluated the strength of DNA damage in solid tumor (HeLa) and leukemia (CCRF-CEM) cells, respectively, induced by low-dose and the prolonged exposure to DFP-10917 compared to treatment with GEM and Ara-C. By comet assay, DFP-10917 was confirmed to induce DNA damage by inducing DNA strand breaks (mainly double-strand breaks) in both cells. On the other hand, GEM and Ara-C did not cause such events at the concentrations and exposure times used, which suggests a marked difference in the mechanisms of action between DFP-10917 and the two deoxycytidine analogs, as regards the pharmacological mechanism of the drugs (Figs. 4 and 5). Furthermore, we investigated the influence of DFP-10917-induced DNA damage on the cell cycle of HeLa cells in vitro and compared the effects to those of GEM. We found that only low-dose $(1 \mu \mathrm{M})$ and long-term exposure (72 h) to DFP-10917 fairly increased the population of cells in the G2/M phase, while 0.003 to $0.03 \mu \mathrm{M}$ GEM used in this study did not lead to such an accumulation of cells in the G2/M phase of the cell cycle (Fig. 6). Our data are consistent with those of previous studies on several leukemia cells in vitro (14-17). Importantly, our in vitro mechanistic experiments were performed based on the finding of which the prolonged infusion of low-dose DFP-10917 attained the regression of tumor growth without any toxicities on human solid and hematological tumor xenografts compared to clinically available deoxycytidine analogs. Accordingly, DFP-10917, when infused consecutively for a long-term period at a low-dose, may be a beneficial therapy, not only for hospitalized, but also for outpatients with advanced and inoperable tumors, including AML and pancreatic cancer. Another clinical phase I/II trial for DFP-10917 administered by continuous infusion is ongoing in patients with relapsed or refractory AML, which failed to respond to treatment with an Ara-C-containing standard regimen (https://www.clinicaltrials.gov/ct2/show/NCT01702155?term=DFP-10917\&rank=1).

In conclusion, based on the cellular metabolism of DFP-10917 and its possible utility strategy, various treatment schedules were investigated using human tumor xenografts in mice and found that the prolonged continuous infusion rather than the short-term administration provided the best outcome for the treatment of the rapid growth of tumor cells in vivo. Such an antitumor activity by DFP-10917 was suggested to be depend on the induction of DNA damage and the subsequent accumulation of cells in the G2/M phase (namely G2/M arrest) of the cell cycle in tumor cells, which is markedly different from the functional mechanisms of other antitumor nucleosides.

\section{Acknowledgements}

The authors would like to express their gratitude to Dr Tatsuhiro Ishida, Tokushima University, for his valuable advice regarding technical issues.

\section{Competing interests}

The authors declare that they have no competing interests. 


\section{References}

1. Noble S and Goa KL: Gemcitabine. A review of its pharmacology and clinical potential in non-small cell lung cancer and pancreatic cancer. Drugs 54: 447-472, 1997.

2. Barton-Burke M: Gemcitabine: A pharmacologic and clinical overview. Cancer Nurs 22: 176-183, 1999.

3. Toschi L, Finocchiaro G, Bartolini S, Gioia V and Cappuzzo F: Role of gemcitabine in cancer therapy. Future Oncol 1: 7-17, 2005.

4. Cole $\mathrm{N}$ and Gibson BE: High-dose cytosine arabinoside in the treatment of acute myeloid leukaemia. Blood Rev 11: 39-45, 1997.

5. Kern W and Estey EH: High-dose cytosine arabinoside in the treatment of acute myeloid leukemia: Review of three randomized trials. Cancer 107: 116-124, 2006.

6. Reese ND and Schiller GJ: High-dose cytarabine (HD araC) in the treatment of leukemias: A review. Curr Hematol Malig Rep 8: 141-148, 2013.

7. Li W, Gong X, Sun M, Zhao X, Gong B, Wei H, Mi Y and Wang J: High-dose cytarabine in acute myeloid leukemia treatment: A systematic review and meta-analysis. PLoS One 9: e110153, 2014.

8. Somasekaram A, Jarmuz A, How A, Scott J and Navaratnam N: Intracellular localization of human cytidine deaminase. Identification of a functional nuclear localization signal. J Biol Chem 274: 28405-28412, 1999.

9. Azuma A, Nakajima Y, Nishizono N, Minakawa N, Suzuki M, Hanaoka K, Kobayashi T, Tanaka M, Sasaki T and Matsuda A: Nucleosides and nucleotides. 122. 2'- $C$-cyano-2'-deoxy-1- $\beta$ D-arabinofuranosylcytosine and its derivatives. A new class of nucleoside with a broad antitumor spectrum. J Med Chem 36 4183-4189, 1993.

10. Azuma A, Hanaoka K, Kurihara A, Kobayashi T, Miyauchi S, Kamo N, Tanaka M, Sasaki T and Matsuda A: Nucleosides and nucleotides. 141. Chemical stability of a new antitumor nucleoside, 2 '- $C$-cyano-2'-deoxy-1- $\beta$-D-arabino-pentofuranosylcytosine in alkaline medium: Formation of 2'- $C$-cyano-2'-deoxy-1- $\beta$-Dribo-pentofuranosylcytosine and its antitumor activity. J Med Chem 38: 3391-3397, 1995.

11. Tanaka M, Matsuda A, Terao T and Sasaki T: Antitumor activity of a novel nucleoside, 2'- $C$-cyano-2'-deoxy-1- $\beta$-D arabinofuranosylcytosine (CNDAC) against murine and human tumors. Cancer Lett 64: 67-74, 1992

12. Azuma A, Huang P, Matsuda A and Plunkett W: Cellular pharmacokinetics and pharmacodynamics of the deoxycytidine analog 2'- $C$-cyano-2'-deoxy-1- $\beta$-D-arabino-pentofuranosylcytosine (CNDAC). Biochem Pharmacol 61: 1497-1507, 2001.

13. Hayakawa Y, Kawai R, Otsuki K, Kataoka M and Matsuda A: Evidence supporting the activity of 2 '- $C$-cyano-2'-deoxy-1- $\beta$-D arabino-pentafuranosylcytosine as a terminator in enzymatic DNA-chain elongation. Bioorg Med Chem Lett 8: 2559-2562, 1998.

14. Azuma A, Huang P, Matsuda A and Plunkett W: 2'-C-cyano2 -deoxy-1- $\beta$-D-arabino-pentofuranosylcytosine: A novel anticancer nucleoside analog that causes both DNA strand breaks and G(2) arrest. Mol Pharmacol 59: 725-731, 2001.

15. Liu X, Guo Y, Li Y, Jiang Y, Chubb S, Azuma A, Huang P, Matsuda A, Hittelman W and Plunkett W: Molecular basis for G2 arrest induced by 2 '- $C$-cyano-2'-deoxy-1- $\beta$-D-arabinopentofuranosylcytosine and consequences of checkpoint abrogation. Cancer Res 65: 6874-6881, 2005.

16. Wang YandLiuX:M<atsudaAandPlunkettW:Repairof 2'- $C$-cyano2 '-deoxy-1- $\beta$-D-arabino-pantofuranosylcytosine-induced DNA single-starand breaks by transcription-coupled nucleotide excision repair. Cancer Res 68: 3881-2889, 2008.

17. Liu X, Wang Y, Benaissa S, Matsuda A, Kantarjian H, Estrov Z and Plunkett W: Homologous recombination as a resistance mechanism to replication-induced double-strand breaks caused by the antileukemia agent CNDAC. Blood 116: 1737-1746, 2010.

18. Huang P, Chubb S, Hertel LW, Grindey GB and Plunkett W: Action of 2',2'-difluorodeoxycytidine on DNA synthesis. Cancer Res 51: 6110-6117, 1991

19. Jiang HY, Hickey RJ, Abdel-Aziz W and Malkas LH: Effects of gemcitabine and araC on in vitro DNA synthesis mediated by the human breast cell DNA synthesome. Cancer Chemother Pharmacol 45: 320-328, 2000.

20. Miura S and Izuta S: DNA polymerases as targets of anticancer nucleosides. Curr Drug Targets 5: 191-195, 2004.

21. Liao W, McNutt MA and Zhu WG: The comet assay: A sensitive method for detecting DNA damage in individual cells Methods 48: 46-53, 2009.
22. Food and Drug Administration, HHS: HHS: International conference on harmonisation; guidance on S9 nonclincal evaluation for anticancer pharmaceuticals; availability. Fed Regist 75: 10487-10488, 2010

23. Cook N, Hansen AR, Siu LL and Abdul Razak AR: Early phase clinical trials to identify optimal dosing and safety. Mol Oncol 9: 997-1007, 2015

24. Burris HA III, Moore MJ, Andersen J, Green MR, Rothenberg ML, Modiano MR, Cripps MC, Portenoy RK, Storniolo AM, Tarassoff $\mathrm{P}$, et al: Improvements in survival and clinical benefit with gemcitabine as first-line therapy for patients with advanced pancreas cancer: A randomized trial. J Clin Oncol 15: 2403-2413, 1997.

25. Sandler AB, Nemunaitis J, Denham C, von Pawel J, Cormier Y, Gatzemeier U, Mattson K, Manegold C, Palmer MC, Gregor A, et al: Phase III trial of gemcitabine plus cisplatin versus cisplatin alone in patients with locally advanced or metastatic non-smallcell lung cancer. J Clin Oncol 18: 122-130, 2000.

26. Spratlin J, Sangha R, Glubrecht D, Dabbagh L, Young JD, Dumontet C, Cass C, Lai R and Mackey JR: The absence of human equilibrative nucleoside transporter 1 is associated with reduced survival in patients with gemcitabine-treated pancreas adenocarcinoma. Clin Cancer Res 10: 6956-6961, 2004.

27. Ho CC, Kuo SH, Huang PH, Huang HY, Yang CH and Yang PC; Ho CC1: Caveolin-1 expression is significantly associated with drug resistance and poor prognosis in advanced non-small cell lung cancer patients treated with gemcitabine-based chemotherapy. Lung Cancer 59: 105-110, 2008.

28. Veerman G, Ruiz van Haperen VW, Vermorken JB, Noordhuis P, Braakhuis BJ, Pinedo HM and Peters GJ: Antitumor activity of prolonged as compared with bolus administration of 2',2'-difluorodeoxycytidine in vivo against murine colon tumors. Cancer Chemother Pharmacol 38: 335-342, 1996.

29. Kirstein MN, Wieman KM, Williams BW, Fisher JE, Marker PH, Le CT, Yee D and Kratzke RA: Short versus continuous gemcitabine treatment of non-small cell lung cancer in an in vitro cell culture bioreactor system. Lung Cancer 58: 196-204, 2007.

30. Rajdev L, Goldberg G, Hopkins U and Sparano JA: A phase I trial of gemcitabine administered as a 96-h continuous intravenous infusion in patients with advanced carcinoma and lymphoma. Med Oncol 23: 369-376, 2006.

31. Tempero M, Plunkett W, Ruiz Van Haperen V, Hainsworth J, Hochster H, Lenzi R and Abbruzzese J: Randomized phase II comparison of dose-intense gemcitabine: Thirty-minute infusion and fixed dose rate infusion in patients with pancreatic adenocarcinoma. J Clin Oncol 21: 3402-3408, 2003.

32. Cappuzzo F, Novello S, De Marinis F, Selvaggi G, Scagliotti GV, Barbieri F, Maur M, Papi M, Pasquini E, Bartolini S, et al: A randomized phase II trial evaluating standard $(50 \mathrm{mg} / \mathrm{min})$ versus low $(10 \mathrm{mg} / \mathrm{min})$ infusion duration of gemcitabine as firstline treatment in advanced non-small-cell lung cancer patients who are not eligible for platinum-based chemotherapy. Lung Cancer 52: 319-325, 2006.

33. Ho DH, Brown NS, Benvenuto J, McCredie KB, Buckels D and Freireich EJ: Pharmacologic studies of continuous infusion of arabinosylcytosine by liquid infusion system. Clin Pharmacol Ther 22: 371-374, 1977.

34. Kreis W, Chaudhri F, Chan K, Allen S, Budman DR, Schulman P, Weiselberg L, Freeman J, Deere $M$ and Vinciguerra V: Pharmacokinetics of low-dose 1-beta-D-arabinofuranosylcytosine given by continuous intravenous infusion over twenty-one days. Cancer Res 45: 6498-6501, 1985.

35. Spriggs DR, Robbins G, Takvorian T and Kufe DW: Continuous infusion of high-dose 1-beta-D-arabinofuranosylcytosine: A phase I and pharmacological study. Cancer Res 45: 3932-3936, 1985.

36. Donehower RC, Karp JE and Burke PJ: Pharmacology and toxicity of high-dose cytarabine by 72-hour continuous infusion. Cancer Treat Rep 70: 1059-1065, 1986.

37. Spriggs DR, Sokal JE, Griffin J and Kufe DW: Low-dose ara-C administered by continuous subcutaneous infusion: A pharmacologic evaluation. Cancer Drug Deliv 3: 211-216, 1986.

38. Bolwell BJ, Cassileth PA and Gale RP: Low-dose cytosine arabinoside in myelodysplasia and acute myelogenous leukemia: A review. Leukemia 1: 575-579, 1987.

39. Stentoft J: The toxicity of cytarabine. Drug Saf 5: 7-27, 1990.

40. Stone RM, Spriggs DR, Dhawan RK, Arthur KA, Mayer RJ and Kufe DW: A phase I study of intermittent continuous infusion high-dose cytosine arabinoside for acute leukemia. Leukemia 4: 843-847, 1990. 
41. Schiller G, Gajewski J, Nimer S, Territo M, Ho W, Lee M and Champlin R: A randomized study of intermediate versus conventional-dose cytarabine as intensive induction for acute myelogenous leukaemia. Br J Haematol 81: 170-177, 1992.

42. Fleming RA, Capizzi RL, Rosner GL, Oliver LK, Smith SJ, Schiffer CA, Silver RT, Peterson BA, Weiss RB, Omura GA, et al: Clinical pharmacology of cytarabine in patients with acute myeloid leukemia: A cancer and leukemia group B study. Cancer Chemother Pharmacol 36: 425-430, 1995.
43. Bishop JF, Matthews JP, Young GA, Szer J, Gillett A, Joshua D, Bradstock K, Enno A, Wolf MM, Fox R, et al: A randomized study of high-dose cytarabine in induction in acute myeloid leukemia. Blood 87: 1710-1717, 1996.

44. Löwenberg B, Pabst T, Vellenga E, van Putten W, Schouten HC, Graux C, Ferrant A, Sonneveld P, Biemond BJ, Gratwohl A, et al; Dutch-Belgian Cooperative Trial Group for Hemato-Oncology (HOVON) and Swiss Group for Clinical Cancer Research (SAKK) Collaborative Group: Cytarabine dose for acute myeloid leukemia. N Engl J Med 364: 1027-1036, 2011. 